children carries a poor prognosis. Their work thus suggests that repeated direct measurements of arterial blood-gas and $\mathrm{pH}$ levels might do much to improve the management of children with severe respiratory tract infections; we would add that repeated electrolyte determinations might also be of value. The use of modern microtechniques greatly reduces the extent to which such investigations disturb a sick child. The mortality rate associated with respiratory tract infections in childhood seems more likely to be reducible by such an approach than by any other at present available to us.

\section{Summary}

Of 22 children with respiratory tract infections who died in Newcastle and Durham hospitals during a 27-month period, 19 were less than 1 year old. Nine had major congenital abnormalities. Bacterial infections were apparently responsible for only 6 of the 22 deaths. Respiratory syncytial virus was the only potential pathogen isolated from eight of the children; it was isolated from necropsy lung specimens in seven of these cases, including all four cases of pneumonia with no apparent bacterial cause; and it was also isolated from the upper respiratory tract and the lung of a child with haemophilus epiglottitis. No other viruses were incriminated in any of the 22 cases. Sudden and substantially irreversible collapse was a common feature, especially in the cases not apparently caused by bacteria. Investigation of the blood-gas levels and biochemical changes in such children is suggested as the most promising approach to improved management.

We gratefully acknowledge the use of clinical notes and reports by numerous colleagues at the Royal Victoria Infirmary (11 cases), Newcastle General Hospital and Dryburn Hospital, Durham (five cases each), and Walker Gate Hospital, Newcastle (one case); also of necropsy reports on the five Dryburn Hospital patients by Dr. J. E. Ennis and on eight of the infirmary patients by Drs. T. Ashcroft, C. Ashton, A. R. Morley, and A. Talerman ; and of histological sections of the lungs from all these patients. We are indebted to many of our laboratory colleagues for technical assistance, and also to the Scientific and Research Subcommittee of the United Newcastle upon Tyne Hospitals for their continued support. During this work one of us (M. D. H.) held a research grant from the Medical Research Council.

\section{REFERENCES}

Beem, M., Wright, F. H., Fasan, D. M., Egerer, R., and Oehme, M. (1962). F. Pediat., 61, 864

Berenberg, W., and Kevy, S. (1958). New Engl. 7. Med., 258, 870 Chanock, R. M., et al. (1961). F. Amer. med. Ass., 176, 647.

DeMuth, G. R., and Sloan, H. (1966). Surgery, 59, 601.

Disney, M. E., Sandiford, B. R., Cragg, J., and Wolff, J. (1960). Brit. med. F., 1, 1407.

Elderkin, F., M., Gardner, P. S., Turk, D. C., and White, A. C. (1965) Ibid, 2,722 .

Hubble, D., and Osborn, G. R. (1941). Ibid, 1, 107

Johnstone, J. M., and Lawy, H. S. (1967). Lancet, 2, 134

Jones, H. M., and Camps, F. E. (1957). Practitioner, 178, 223

Morrison, B. (1955). Lancet, 2, 737.

Simpson, H., and Flenley, D. C. (1967). Ibid, 1, 7.

Turk, D. C., and May, J. R. (1967). Haemophilus Influenzae: Its Clinical Importance. London

\title{
Further Experience of Reactions, Especially of a Cerebral Nature, in Conjunction with Triple Vaccination: A Study Based on Vaccinations in Sweden 1959-65
}

JUSTUS STRÖM,* M.D.

The previous report concerning reactions in conjunction with triple vaccination in Sweden during the period 1954-8 (Ström, 1960) aroused considerable attention and also criticism (Malmgren et al., 1960; Hellström, 1962). To question the propriety of recommending universal vaccination against whooping-cough in all circumstances and in all countries was naturally a serious matter. Even if the predominant view is still that pertussis vaccination is of such value that it should be universally recommended, certain authorities (Wilson and Miles, 1964 ; Herrlich, 1965 ; Ehrengut, 1966) express some doubt on the point.

However, one absolute requirement must be that the complications occurring in connexion with vaccination are carefully observed and recorded. It is also important to note whether in due course the incidence or the severity of the side-effects is reduced. A further requirement is to ascertain whether the complications that may occur are likely to affect the incidence and fulfilment of vaccination.

Material.-A study was made of children under the control of child welfare clinics. Every vaccination clinic was sent an annual questionary for notification of reactions that had occurred. All children's hospitals in the country were asked to report annually concerning treated cases of postvaccinal complications. For the years 1962-4, furthermore, special reports were requested from the welfare clinics on whether vaccination had been carried out.

* Hospital for Infectious Diseases, Stockholm, Sweden

\section{Results}

Table I shows the various types of cerebral reactions observed. Of the 167 cases 81 were admitted to hospital.

TABLE I.-Cerebral Reactions in Conjunction with Triple Vaccinations

\begin{tabular}{|c|c|c|c|c|c|c|c|}
\hline Year & $\begin{array}{l}\text { Cere- } \\
\text { bral } \\
\text { Injury }\end{array}$ & $\begin{array}{c}\text { Convul- } \\
\text { sions }\end{array}$ & $\begin{array}{c}\text { Hyps- } \\
\text { arrhythmia }\end{array}$ & Shock & $\begin{array}{c}\text { Irritability } \\
+ \\
\text { Abnormal } \\
\text { Spinal } \\
\text { Fluid }\end{array}$ & $\begin{array}{l}\text { Abnormal } \\
\text { Screaming }\end{array}$ & Total \\
\hline \multirow[t]{2}{*}{$\begin{array}{l}1959 \\
1960 \\
1961 \\
1962 \\
1963 \\
1964 \\
1965\end{array}$} & $\begin{array}{l}1 \\
1\end{array}$ & $\begin{array}{r}7 \\
5 \\
12 \\
12 \\
9 \\
11 \\
24\end{array}$ & $\frac{1}{1}$ & $\begin{array}{r}3 \\
7 \\
3 \\
5 \\
9 \\
11 \\
16 \\
\end{array}$ & 2 & $\begin{array}{r}4 \\
3 \\
1 \\
1 \\
1 \\
4 \\
10 \\
\end{array}$ & $\begin{array}{l}16 \\
16 \\
16 \\
19 \\
21 \\
27 \\
52 \\
\end{array}$ \\
\hline & 3 & 80 & 4 & 54 & 2 & 24 & 167 \\
\hline
\end{tabular}

Cerebral injury was thus reported in three cases, which are described in some detail.

Case 1.-The child was said to have developed normally. The first injection was given at the age of 5 months. The patient was febrile for two to three days, and for one week was very drowsy. The second injection, given six weeks later, produced the same reaction, but the child then became extremely listless, " did not react to anything," and convulsive attacks started one week after the injection. The attacks increased in frequency and duration and were followed by rapid mental regression. E.E.G. showed great paroxysmal activity. While the child was in hospital, at 7 months 
of age, decerebrate rigidity was diagnosed, and encephalography revealed cerebral atrophy. Toxoplasmosis and Wassermann reactions were negative.

Case 2.-This child was healthy and of normal development. There was no reaction after the first injection. The patient had a convulsive attack, and a temperature of $39.5^{\circ} \mathrm{C}$. on the ninth day after the second injection at the age of 7 months. Next day there was a new attack-clonic on the right side-followed by paralysis. Lumbar puncture revealed albumin $34 \mathrm{mg} . / 100 \mathrm{ml}$. and 2 cells. On the following day there were similar convulsions and paralysis, and complete loss of contact. E.E.G. showed incessant paroxysmal activity over the entire left hemisphere. Increasingly severe convulsions occurred. The child was afebrile after three weeks, when a stage of complete decerebration developed. A special examination showed a heavy transient rise of total protein in the cerebrospinal fluid and a rise of the gammaglobulin fraction in blood and fluid. Culture for bacteria was negative. No virus was found in nasopharyngeal secretion, cerebrospinal fluid, or faeces. The senior physician expressed his suspicion of a direct relation to triple vaccination, and the National Bacteriological Laboratory declared that "vaccination as an aetiological factor could not be excluded."

Case 3.-This child, birth weight 2,840 g., had a normal birth and normal psychomotor development. The second injection was given at $4 \frac{1}{2}$ months of age. Four hours after the injection the child had a convulsive attack lasting a few seconds in the left half of the face and arms, followed by flaccidity in the left arm and leg, and slightly, too, in the right arm ; was not unconscious, and was taken to hospital with a temperature of $38.2^{\circ} \mathrm{C}$., but otherwise unaffected. Convulsions returned six weeks later, starting in the right half of the face and in the right arm and leg. After half an hour convulsions followed in the left side. A similar attack occurred on two other occasions. After a severe attack at 11 months of age the child was admitted to hospital. Wassermann reaction and toxoplasmosis were negative. E.E.G. showed grave abnormality. Encephalography revealed cortical and central atrophy on the right side. Later there was considerable regression in development.

Convulsions and Shock.-Clonic convulsions alone occurred in 80 cases. Certain remarkable states of persistent tonic cramp also seem to occur at times. The shock (54 cases) is characterized chiefly by a sudden loss of consciousness lasting for a few minutes up to half an hour, accompanied by flaccidity and pallor or cyanosis, or both.

Reaction and Ordinal Number of Injection.-Convulsions occurred in 42 cases after the first injection, in 28 after the second, and in 9 after the third (in one case after a fourth), and shock in 34 cases after the first, 19 after the second, and 1 after the third. Thus most cases occurred after the first injection.

Time interval between injection and reaction is shown in Table II (data are lacking in 20 cases of convulsions and two of shock). The reaction usually came on during the first day, and in most cases in the first six hours. Two cases of convulsions, however, occurred on the second day, one case on the sixth, and one on the seventh. As regards the two latter, it may be mentioned that one child had a temperature of $39^{\circ} \mathrm{C}$. for a whole week, which was followed by convulsions, at first seven or eight a day, then diminishing in frequency and ceasing after a month. The second child had a convulsive attack without fever on the sixth day after the first injection. The convulsions returned five hours after the second injection, with a temperature of $38.1^{\circ} \mathrm{C}$. Convulsions were observed on two other occasions later in the year. In two of the cases of cerebral injury the convulsions also came late. Repeated convulsive attacks were described in some other children. An example was a child who had convulsions six hours after the injection. An hour later they returned, accompanied by a temperature of $38.1^{\circ}$ C. Three days later there were renewed attacks, the temperature being $37.4^{\circ} \mathrm{C}$. Another child had convulsions

TABLE II.-Time Interval Between Injection and Reaction

\begin{tabular}{c|c|c|c|c|c|c|c}
\hline \multirow{2}{*}{$\begin{array}{c}\text { Type } \\
\text { of } \\
\text { Reaction }\end{array}$} & \multicolumn{4}{|c|}{ Hours after Injection } & \multicolumn{3}{c}{ Day after Injection } \\
\cline { 2 - 8 } & $0-3$ & $4-6$ & $7-12$ & $13-24$ & 2nd & 6 th & 7th \\
\hline $\begin{array}{l}\text { Convulsions } \\
\text { Shock }\end{array}$ & 17 & 18 & 9 & 12 & 2 & 1 & 1 \\
\hline
\end{tabular}

one hour after the vaccination, again after seven hours, four times during the following night, and seven times on the next day.

Temperature at Time of Reaction.-The temperature was reported in only 26 cases of convulsions and 11 of shock (Table III). Fever was not always present. In 9 out of 26 cases of convulsions and in 6 out of 11 cases of shock the temperature was not above $38^{\circ} \mathrm{C}$.

$$
\text { TABLE III.-Body Temperature at Onset of the Reaction }
$$

\begin{tabular}{l|c|c|c|c|c|c|c}
\hline & \multicolumn{8}{|c}{ Temperature ( ${ }^{\circ} \mathrm{C}$.) } \\
$\begin{array}{c}\text { Type of } \\
\text { Reaction }\end{array}$ & $-37 \cdot 4$ & $\begin{array}{c}37 \cdot 5- \\
38\end{array}$ & $\begin{array}{c}38 \cdot 1- \\
38 \cdot 5\end{array}$ & $\begin{array}{c}38 \cdot 6- \\
39\end{array}$ & $\begin{array}{c}39 \cdot 1- \\
39 \cdot 5\end{array}$ & $\begin{array}{c}39 \cdot 6- \\
40\end{array}$ & $>40$ \\
\hline $\begin{array}{c}\text { Convulsions } \\
\text { Shock }\end{array}$ & 5 & 4 & 3 & 8 & 2 & 3 & 1 \\
\hline
\end{tabular}

Hypsarrhythmia was reported in two children two to three days after the vaccination and in two others after a week.

Persistent uncontrollable screaming was included only if the state lasted for more than 12 hours or necessitated admission to hospital.

Meningeal Involvement.-Lumbar puncture was performed in nine children who had convulsions: in six the findings were normal and in three abnormal. The latter cases were also clinically more severe. Twenty-four hours after the injection one child had a general attack, which recurred several times during the following week. The cerebrospinal fluid showed 9 cells. The second child was very irritable on the day of injection, had diarrhoea on the second day and a temperature of $37.8^{\circ} \mathrm{C}$., and on the third day had convulsions and a temperature of $39.4^{\circ} \mathrm{C}$. These symptoms recurred on the fourth day and for a time the child was in a moribund state (tachycardia, bigeminy, enlarged heart). Cerebrospinal fluid showed: $\mathrm{P}+, \mathrm{N}+, 12$ cells. The third child had fever on the day after the vaccination, thereafter vomiting for several days, and again fever, $38-39^{\circ} \mathrm{C}$. with convulsions. Lumbar puncture showed 28 cells. Lumbar punctures were performed in four of the shock cases. In two the findings were normal, one had a borderline cell content ( 5 cells/cu. $\mathrm{mm}$.), and one had a high protein level $(81 \mathrm{mg} . / 100 \mathrm{ml}$.) In the latter case the shock condition recurred once. Of special interest are two patients who clinically showed only very moderate irritability but nevertheless a distinct meningeal involvement. In one case the child was whiny and irritable on the day of injection and had a temperature of $39^{\circ} \mathrm{C}$. The next day the temperature was $40.1^{\circ} \mathrm{C}$. and the fontanelle was bulging. Lumbar puncture showed 30 cells. The other child was also moderately irritable and the lumbar puncture showed 57 cells. In all, therefore, six children on whom lumbar puncture was performed showed signs of meningeal involvement.

The incidence of cerebral reactions is shown in Table IV. Reaction in the form of convulsions, shock, and meningeal involvement occurred in $1: 3,600$ vaccinated children (convulsions $1: 6,500$, shock $1: 9,500$ ). Including abnormal screaming the incidence is $1: 3,100$.

\section{Other Reactions}

High temperature has been reported annually in 50 to 150 cases. A temperature above $40^{\circ} \mathrm{C}$. is not unusual, the record being $42^{\circ} \mathrm{C}$.

TABLE IV.-Incidence of Cerebral Reactions After Triple Vaccination

\begin{tabular}{c|c|c|c}
\multicolumn{2}{c}{ 1959-65. (Cases of } & Abnormal Screaming & Not Included) \\
\hline Year & No. of Vaccinees & Cerebral Reactions & Incidence \\
\hline 1959 & 63,141 & 12 & $1: 5,300$ \\
1960 & 55,042 & 13 & $1: 4,200$ \\
1961 & 64,226 & 15 & $1: 4,300$ \\
1962 & 68,225 & 18 & $1: 3,800$ \\
1963 & 76,361 & 20 & $1: 3,800$ \\
1964 & 90,697 & 23 & $1: 3,900$ \\
1965 & 98,584 & 42 & $1: 2,300$ \\
\hline & 516,276 & 143 & $1: 3,600$
\end{tabular}


One child had a temperature of $40^{\circ} \mathrm{C}$. for three days, and the next injection, with only one-tenth of the previous dose, produced the same reaction.

In recent years rashes have been reported in 15 to 20 cases annually. Exanthema of a morbilliform character or erythema appears to be most common. The same kind of morbilliform exanthema of 48 hours' duration appeared in two children after both the first and the second injection. Oedema of the face, hands, and feet, accompanied or unaccompanied by erythema, has been observed. In 29 cases on which detailed reports were made the exanthema occurred in 15 cases after the first injection, in 11 after the second, and in three after the third; and in respect of time, in 19 of 27 cases on the first day, in six on the second, and in one case each on the third and fourth days.

Local skin reactions, particularly in the form of sterile abscesses, were very common up to 1963 , but have since become rare, as aluminium has been eliminated from the vaccine.

Gastrointestinal symptoms were occasionally reported. Vomiting and diarrhoea occurred after a day or so, lasting for a couple of days to roughly a week. Repeated injections produced the same effect.

\section{Incidence and Fulfilment of Triple Vaccination}

Special reports were requested for children born in 1962-4. Figures were obtained concerning 208,186 children (out of a total of 235,283 -that is, $88.4 \%$ ). Of this number 156,802 $(75.3 \%)$ had been completely vaccinated, $17,342(8.3 \%)$ incompletely, and $34,042(16.4 \%)$ not at all.

The reasons for non-vaccination or incomplete vaccination are given in Table $\mathrm{V}$. The reason for non-vaccination in over half of the cases was the parents' refusal. This corresponds to $8.6 \%$ of the total number of children. Medical reasons were reported in only $5.2 \%$-that is, about $1 \%$. Incomplete vaccination would seem to be due chiefly to a reaction to earlier injection. Medical reasons and parents' refusal were the cause of interrupted vaccination in roughly equal numbers of cases-1.4 and $1.5 \%$ respectively, together representing about $3 \%$. This figure is naturally a minimum, as the "unknown" group undoubtedly contains some cases attributable to these two causes. The " other cause" group includes mostly children who had moved or were no longer brought in for control, etc.

TABle V.-Reasons for Non-vaccination and Incomplete Vaccination

\begin{tabular}{|c|c|c|c|c|c|}
\hline Vaccination & $\begin{array}{c}\text { Medical } \\
\text { Cause }\end{array}$ & $\begin{array}{l}\text { Parents' } \\
\text { Refusal }\end{array}$ & $\begin{array}{l}\text { Other } \\
\text { Cause }\end{array}$ & $\begin{array}{l}\text { Unknown } \\
\text { Cause }\end{array}$ & $\begin{array}{l}\text { Diphtheria- } \\
\text { Tetanus } \\
\text { Vaccination } \\
\text { Instead }\end{array}$ \\
\hline $\begin{array}{ll}\text { Not done (\%) } & \ldots \\
\text { Incomplete (\%) } & \ldots\end{array}$ & $\begin{array}{r}5 \cdot 2 \\
17 \cdot 1\end{array}$ & $\begin{array}{l}52 \cdot 7 \\
18 \cdot 3\end{array}$ & $\begin{array}{l}10 \cdot 9 \\
33 \cdot 4\end{array}$ & $\begin{array}{l}27 \cdot 5 \\
30 \cdot 7\end{array}$ & $\begin{array}{l}3.7 \\
0.5\end{array}$ \\
\hline
\end{tabular}

\section{Discussion}

The first question on which the material presented throws some light is the classification of the cerebral reactions as serious or negligible. As a rule, naturally the main emphasis was on encephalopathies, which caused serious injury ; while convulsions, for example, were regarded as a simple febrile reaction. This may be so in some cases, but the present study shows that in nine out of 26 cases the temperature was normal or at most $38^{\circ} \mathrm{C}$. Furthermore, pleocytosis was found in the cerebrospinal fluid of three out of nine children on whom lumbar puncture was performed. In several cases, too, there was a marked tendency towards repeated convulsive attacks, contrary to the usual situation in febrile convulsions.

Provocation of hypsarrhythmia was observed in four cases. Similar observations have been made by others (Baird and Borofsky, 1957 ; Chao et al., 1957 ; Bower and Jeavons, 1960 ; Kringelbach and Senstius, 1965).
Shock appears to be still less dependent on the temperature. In six out of 11 cases this was normal or at most $38^{\circ} \mathrm{C}$. In one of the four cases in which lumbar puncture was performed the protein content of the cerebrospinal fluid was raised; another case was on the borderline of pleocytosis.

In two children with relatively mild irritability the cerebrospinal fluid findings were distinctly abnormal. It would be of value to know the situation as regards abnormal screaming, which is not so unusual, and which, because of its intensity and difficulty of appeasement, gives the impression of being of cerebral origin (Hopper, 1961).

With these facts in mind it may be asserted that the convulsions, shock, and abnormal irritability observed after triple vaccination cannot always be regarded as commonplace general symptoms but reflect an objectively demonstrable cerebral reaction. The provocation of hypsarrhythmia supports this view. This is a rather more serious aspect of the problem, and the dividing line between what should and should not be regarded as a severe reaction becomes more fluid. Happily, in the short-term view at least, these reactions appear to have a favourable prognosis.

Pathogenetically the endotoxin of the pertussis bacteriaa well-known neurotoxic agent-must be the factor responsible for the cerebral reactions. The fact that most reactions occur after the first injection is against an allergic origin. Certain observations, however, show a quicker and more severe effect of subsequent injections.

Other observed reactions, such as erythema, exanthema, oedema, and gastrointestinal symptoms, also have a rapid onset, usually after the first injection. But there must be an individual predisposition as well, as it was repeatedly found that the same symptoms recurred after subsequent injections.

To sum up, the vaccination reactions may be regarded chiefly as manifestations of a toxic effect, an individual predisposition being of some significance. The allergic element, on the other hand, appears to fall into the background.

As regards the incidence of different reactions to vaccination, the study shows, for children born during 1962-4, that in at least $3 \%$ the side-effects were so serious that further vaccinations were not given. In respect of neurological symptoms there seems to be a tendency to an increase compared with my previous report, in which the incidence was $1: 6,000$ as against the present $1: 3,600$ - uncontrollable screaming excepted. This is probably only an apparent increase due to keener observation on the part of the medical staff. Only three cases of destructive encephalopathy have occurred in these seven years $(1: 170,000)$ as against the figure of $1: 50,000-60,000$ established by the Board of Health (Malmgren et al., 1960) after the earlier study.

If one further differentiates the present material another group with rather more marked symptoms is distinguishablethat is, the cases in which there was serous meningitis and/or a pronounced tendency to repeated attacks of convulsions, or provocation of hypsarrhythmia, altogether 15 cases. The incidence of these reactions is $1: 34,000$ vaccinees ; the remaining cases-that is, the milder, quickly passing reactionsnumber 125 ( $1: 4,000)$.

Finally, a general reflection. It may be seen that reactions following triple vaccination are unusually numerous in Sweden compared with other countries. But it must be remembered that our figures are based on very thorough centralized supervision, to which there is hardly any counterpart in other countries. Only by means of annual reports from all vaccinating bodies in a standardized form can a reasonably clear picture be gained. Experience shows that a general recording duty for physicians in fact results in reports of only a few reactions. This it is extremely important to note in times when vaccinations are increasing every day, and, through the action of our health authorities, tend to become a routine and to be virtually compulsory. The more this happens the more necessary it is to maintain a check on the side-effects, especially in combating 
diseases which, with rising standards of hygiene and public services, are in themselves assuming milder forms (Ström, $1960,1967)$.

\section{Summary}

Among 516,276 triple-vaccinated children in Sweden from 1959 to 1965 neurological reactions to the vaccination occurred in 167 cases-destructive encephalopathy 3, convulsions 80, hypsarrhythmia 4, shock 54, uncontrollable screaming 24, serous meningitis 2 . Serous meningitis was also found in three out of nine examined cases of convulsions, and elevated protein in cerebrospinal fluid in one out of four examined cases of shock. Apart from these objective signs of meningeal involvement in certain cases, the study shows that in conjunction with both convulsions and shock there may be no or very little rise of temperature. The convulsive symptoms therefore cannot be classified as a matter of course as simple febrile convulsions.

The incidence of neurological reactions was $1: 3,600 \mathrm{vac}-$ cinated children $(1: 3,100$ if cases of persistent uncontrollable screaming are included), a rise in relation to the figure of $1: 6,000$ reported in a study from the years 1954 to 1958 . The rise is probably merely apparent, however, owing to the more watchful eye that is kept on these conditions. The more severe reactions leading to permanent injury seem to have decreased.

Analysis of the vaccinations of 208,186 children showed that $75.3 \%$ had been completely vaccinated. The figure for the non-vaccinated was $16.4 \%$, rather more than half of them due to the parents' refusal. Vaccination had not been completed in $8.3 \%$; in at least $3 \%$ the reason was probably the severe reaction to a preceding vaccination.

Apart from neurological reactions, erythema, exanthema, oedema, and gastrointestinal symptoms have also been reported. The great majority of reactions occurred after the first injection. Repeated injection appeared to produce the same reaction.

All forms of reaction can be explained as being of toxic origin. An allergic mechanism would appear to be of relatively limited significance ; a certain individual predisposition, however, seems to be a factor to reckon with.

Finally, it is emphasized that when nation-wide vaccination is recommended detailed information should be required concerning postvaccinal reactions, as is done in Sweden in conjunction with triple vaccination.

\section{REFERENCES}

Baird, H. W., and Borofsky, L. G. (1957). 7. Pediat., 50, 332.

Bower, B. D, and Jeavons, P. M. (1960), Brit. med. 7., 2,1453

Chao, D. H.-C., Taylor, F. M., and Druckman, R. (1957). \%. Pediat., 50,670 .

Ehrengut W. (1966). Impffibel, p. 244 . Stuttgart.

Hellström, B. (1962). Brit. med. $\dot{y}_{.,}, 2,1089$

Herrlich, A. (1965). Handbuch der Schutzimpfungen, p. 705. Berlin. Hopper, J. M. H. (1961). Med. Offr., 106, 241.

Kringelbach, J., and Senstius, J. (1965). Nord. Med., 74, 1293.

Malmgren, B. Vahlquist, B., and Zetterström, R. (1960).' Brit. med. F., 2, 1800

Ström, J. (1960). Ibid., 2, 1184

Wilson, G. S. and Miles, A. A. (1964). Topley and Wilson's Principles of Bacteriology and Immunity, 5th ed., p. 2008. London.
Although much work has been done on clinical aspects of Burkitt's lymphoma, and intense interest has been shown in the relatively high rate of remissions and even "cures" among patients with this disease, there has been little analysis of longterm survival. The major reason for this has been the apparently enormous and seemingly insurmountable problems of keeping track of patients in the developing countries of Africa.

Clifford, working in Kenyatta National Hospital, Nairobi, Kenya, has been able to circumvent this problem to a very large extent by keeping patients in hospital for extended periods, and to date his series (Clifford, 1966 ; Pike, 1966) is the only major one in which complete survival information on the vast majority of patients is available.

Ideas on survival of patients attending Mulago Hospital, Kampala, Uganda, have been based on those known to have died plus those who continued to return to the follow-up clinic, but the fate of upwards of $50 \%$ of the patients leaving the hospital has not been known (Burkitt et al., 1965 ; Burkitt, 1966). However, by combining the data gathered by Mr. D. Burkitt and Mr. A. Lubega (the Kampala Cancer Registry

W.H.O. Senior Lecturer in Epidemiology, Department of Preventive Medicine, Makerere Medical School, P.O. Box 2072, Kampala, Uganda.

+ Member of the M.R.C. Statistical Research Unit, 115 Gower Street, London W.C.1, on secondment to the Department of Pathology, Makerere Medical School.

¥ Medical Assistant. Employed by Dr. Morrow under the U.S. National Cancer Institute (N.I.H.) Contrai t No. PH-43-67-47.

An early draft of this paper was read at the East African Medical Research Council's Conference on "Cancer in Africa" which took place in Nairobi, Kenya, from 11-14 January 1967. social worker) with the data we have ourselves collected since November 1966 it has been possible to obtain survival information on 74 of the $80^{1}$ patients in a defined subpopulation of cases attending Mulago Hospital. This paper reports our findings in this group.

\section{Clinical Material}

The present study comprises the 80 patients diagnosed (microscopically, clinically, or at necropsy) as having Burkitt's lymphoma, who presented for the first time at Mulago Hospital between 1 January 1961 and 31 December 1965, and whose place of residence at onset date was in East or West Mengo Districts of Uganda (as demarcated on the last Ugandan Census in $1959^{2}$ ).

The East and West Mengo Districts, with a population of approximately $1 \frac{1}{2}$ million, comprise an area around Kampala with a radius of about $110 \mathrm{~km}$. (70 miles). To have extended the follow-up to include further districts of Uganda would have provided rapidly diminishing returns for the extra effort and expense involved.

'A table may be obtained from the authors giving for each of the 80 patients : reference number, age, sex, date of presentation at Mulago Hospital, length of history at that date, tumour involvement at presentation staging of the disease, if and when microscopically proved if and when if and when treatment stared and what it was (though not the dose as this was too often unknowable from the notes), date last seen, and condition, length of survival, dates of discharge "improved," dates of recurrences after discharge improved, sites of recurrences, and

therapy given.
${ }^{2}$ East African Statistical Department, Nairobi/Entebbe, 1960. 